\title{
Effects of parabens on antioxidant system and oxidative damages in Nile tilapia (Oreochromis niloticus)
}

\author{
Daniele C. Silva $^{\mathrm{a}}$, Lenard Serrano ${ }^{\mathrm{a}}$, Thiessa M.A. Oliveira ${ }^{\mathrm{a}}$, Adrislaine S. Mansano ${ }^{\mathrm{b}}$, \\ Eduardo A. Almeida ${ }^{c}$, Eny M. Vieira ${ }^{a, *}$ \\ a São Carlos Institute of Chemistry, University of São Paulo, Av. Trabalhador São Carlense, 400, 13560-970 São Carlos, SP, Brazil \\ ${ }^{\mathrm{b}}$ Department of Ecology and Evolutionary Biology, Federal University of São Carlos, Rodovia Washington Luis, km 235, 13565-905 São Carlos, SP, Brazil \\ ${ }^{c}$ Department of Chemistry and Environmental Sciences, Paulista State University (IBILCE/UNESP), Cristóvão Colombo, 2265, 15054-000 São José do Rio Preto, SP, \\ Brazil
}

\section{A R T I C L E I N F O}

\section{Keywords:}

Paraben

Fish

Biomarkers

Oxidative stress

Antioxidant enzymes

\begin{abstract}
A B S T R A C T
In this study, effects of parabens on antioxidant defenses and oxidative damages in gills and liver of Nile tilapia (Oreochromis niloticus) were evaluated. Adult Nile tilapia were exposed to methyl, ethyl, propyl, butyl and benzylparaben and a mixture of methyl and propylparaben for 6 and 12 days. The biomarkers analyzed were superoxide dismutase (SOD), catalase (CAT), glutathione peroxidase (GPx), glutathione reductase (GR), total glutathione (GSH-t) and lipid peroxidation measured by malondialdehyde (MDA) content. Results indicated that exposure to parabens caused biochemical changes in gill and liver cells, which in turn modulated enzymatic and non-enzymatic antioxidants in Nile tilapia. SOD, GPx and GR activity significantly increased in gills and liver after exposure to most parabens. CAT activity had little (liver) or no alteration (gills) in this fish species after treatment with parabens. GSH-t content in liver decreased after 6 days of exposure to parabens, but after 12 days, GSH-t levels increased in liver in all treatments, indicating an antioxidant adaptation to exposure to sublethal doses of parabens. Regarding the MDA levels, no alterations were observed in gills compared to control and in liver the MDA content was reduced after $12 \mathrm{~d}$ of exposure to ethylparaben, butylparaben and paraben mixture, indicating no lipid peroxidation in the analyzed tissues. Our results demonstrate parabens-induced adaptive responses in fish, which were important in the protection against oxidative damages.
\end{abstract}

\section{Introduction}

With the increased use of pharmaceuticals and personal care products for the human population, various anthropogenic substances are continuously released into aquatic environments (Terasaki et al., 2012) through domestic and industrial wastewater (Błędzka et al., 2014). As the sewage treatment plants in most countries do not have an effective removal of parabens, they can be found in surface water samples at concentrations ranging from 0.001 to $52.1 \mu \mathrm{g} \mathrm{L}^{-1}$ (e.g. CzarczyńskaGoślińska et al., 2017; Galinaro et al., 2015; Li et al., 2016; Yamamoto et al., 2011) and may cause toxic effects on non-target organisms, representing a threat to aquatic ecosystems functioning.

Parabens are widely used as preservatives in foods, cosmetics and pharmaceutical products (Ramaswamy et al., 2011) since they act as antimicrobial agents. They are alkyl ester derivatives of p-hydroxybenzoic acid, where the ester functional group is located at the 4carbon of the aromatic ring (Ley et al., 2006). Lipophilic character of parabens increases as the length of the carbon chain of the alkyl group and the molecular weight grows, aspect this that increases the potential preservative of the product (Núñez et al., 2010). Methyl-, ethyl-, propyl-, butyl- and benzylparaben are some of the commercially available parabens. Among them, methylparaben and propylparaben are the most commonly used and are often present in the products together (Xue and Kannan, 2016). Parabens are largely used due to their excellent features such as low reactivity, broad spectrum of antimicrobial activity, high chemical stability (for a wide temperature and pH range), odorless, colorless, non-volatile, low costs of production and they do not change consistency or color of formulations (Błędzka et al., 2014; Soni et al., 2005).

Although parabens are generally considered as safe ingredients, several studies have raised concerns on the safety of parabens (Darbre and Harvey, 2008; Tavares et al., 2009; Xue and Kannan, 2016). Recent reports indicate that exposure to parabens through ingestion, inhalation, or dermal absorption may modulate or disrupt the endocrine system and induce oxidative stress, which may cause deleterious effects in animals and humans (Kang et al., 2013). In addition, parabens can

\footnotetext{
* Corresponding author.

E-mail address: eny@iqsc.usp.br (E.M. Vieira).
} 
accumulate in the tissues of organisms due to the constant exposure to low concentrations and cause changes in biochemical, physiological and reproductive processes of aquatic organisms. Recently, Xue et al. (2015) and Xue and Kannan (2016) reported bioaccumulation of parabens and their metabolites in marine mammals, fish and birds; as well as the biomagnification potential of paraben in a marine food web.

Despite the presence of parabens in the aquatic environment and their toxicity to biota, few studies have focused on oxidative stress induced by parabens in aquatic species. Oxidative stress occurs in organisms when the equilibrium between the reactive oxygen species (ROS) production and the antioxidant defenses is altered, which can lead to lipid peroxidation, membrane destabilization, DNA damage and protein degradation in cells (Sakuragui et al., 2013). Analyzing oxidative stress markers is important to evaluate the effects of chronic exposure under sublethal doses of parabens. Nevertheless, most of the information available in literature for fish is about the estrogenic activity of these compounds (Alslev et al., 2005; Terasaki et al., 2009) and adverse effects on reproduction, development and fertility (Dambal et al., 2017). In rodent models, butylparaben can cause oxidative stress by inhibiting antioxidants (Shah and Verma, 2011). Methylparaben exposure may induce alterations in antioxidant system as well as increase lipid peroxidation in zebrafish embryos (Ateş et al., 2018). To date, studies on the effects of methyl and butylparaben on oxidative stress biomarkers in fish are still limited (e.g. Ateş et al., 2018; Brown et al., 2018) and for some parabens, such as ethyl, propyl and benzylparaben, the effects on antioxidant defenses are unknown.

The aim of the present study was to evaluate the antioxidant system biomarkers responses and oxidative damage in gills and liver of Nile tilapia (Oreochromis niloticus) after 6 and 12 days of exposure to methyl, ethyl, propyl, butyl and benzylparaben and a mixture of methyl and propylparaben. For this purpose, enzymatic and non-enzymatic antioxidants (superoxide dismutase - SOD, catalase - CAT, glutathione peroxidase - GPx, glutathione reductase - GR, total glutathione - GSHt) and the malondialdehyde (MDA) level were selected as biochemical biomarkers. In addition, the acute toxicity of parabens to Nile tilapia was evaluated.

\section{Material and methods}

\subsection{Chemicals}

Methylparaben (MeP), ethylparaben (EtP), propylparaben (PrP), butylparaben (BuP) and benzylparaben (BeP) were purchased from Sigma Aldrich with purities $\geq 99 \%$. The stock solutions of parabens were prepared in HPLC-grade methanol (Panreac, Spain).

\subsection{Test organisms}

Male Nile tilapia adults (Oreochromis niloticus) (3-5 months old, body size $10-15 \mathrm{~cm}$ ) were acquired from Fazolin fish farming, Socorro, São Paulo, Brazil. Fish were acclimated in $250 \mathrm{~L}$ indoor stock-tanks with dechlorinated water for 15 days prior to the assays and kept under controlled temperature $\left(27 \pm 1{ }^{\circ} \mathrm{C}\right)$, photoperiod $(16: 8 \mathrm{~h} \mathrm{light/dark})$ and constant aeration. The animals were fed with commercial fish food once a day during the experimental period. This study was approved by the Ethics Committee for Animal Use of the University of São Paulo (USP), Campus Ribeirão Preto, Brazil - protocol number 12.1.382.53.5.

\subsection{Acute toxicity tests}

Acute toxicity tests with Nile tilapia followed the USEPA guidelines (USEPA, 2002). Based on the results from Dobbins et al. (2009), the tests were carried out at the following concentration ranges: 2.1-16.9 $\mathrm{mg} \mathrm{L}^{-1}$ of benzylparaben, $2.7-21.5 \mathrm{mg} \mathrm{L}^{-1}$ of butylparaben, $3.1-24.8 \mathrm{mg} \mathrm{L}^{-1}$ of propylparaben, $5.5-43.9 \mathrm{mg} \mathrm{L}^{-1}$ of ethylparaben, and $17.1-136.5 \mathrm{mg} \mathrm{L}^{-1}$ of methylparaben. Besides a control, a solvent control $(0.1 \%$ methanol, v/v) was included in the tests. Parabens exposure was performed in glass aquariums filled with $20 \mathrm{~L}$ static exposure medium with constant aeration and without feeding. Tests were conducted using ten replicates per treatment with one fish per replicate $(n=10)$. Five test concentrations besides a control were tested. After $48 \mathrm{~h}$ exposure, the mortality was evaluated and the median lethal concentration (LC50) was determined for each paraben.

\subsection{Exposure of animals for biochemical assays}

The animals were randomly divided into seven groups of six fish $(n=6)$, with each fish individually placed in one of 42 aquariums containing $20 \mathrm{~L}$ of dechlorinated tap water (one fish per aquarium). Fish remained for two days in aquariums for acclimation period. The groups were then exposed for 6 and 12 days to one of the following treatments: methylparaben $\left(4.0 \mathrm{mg} \mathrm{L}^{-1}\right)$; ethylparaben $\left(4.0 \mathrm{mg} \mathrm{L}^{-1}\right)$; propylparaben $\left(4.0 \mathrm{mg} \mathrm{L}^{-1}\right)$; butylparaben $\left(4.0 \mathrm{mg} \mathrm{L}^{-1}\right)$; benzylparaben $\left(4.0 \mathrm{mg} \mathrm{L}^{-1}\right)$; mixture of methyl and propylparaben $\left(6.0 \mathrm{mg} \mathrm{L}^{-1}\right.$ methyl $+1.7 \mathrm{mg} \mathrm{L}^{-1}$ propyl); and one group remained in aquariums without contaminant (control group). A solvent control group $(0.1 \%$ methanol, v/v) was also included in the tests. Based on acute toxicity tests, the concentration of $4.0 \mathrm{mg} \mathrm{L}^{-1}$ was selected because it was the lowest sublethal concentration for Nile tilapia (mortality less than 10\%) considering all the selected parabens. Concentrations of methyl and propylparaben mixture were selected based on preliminary acute toxicity tests using values close to $10 \%$ of $\mathrm{LC}_{50}$ for these compounds. The test solutions were renewed every two days to maintain water quality and compound concentrations. After the exposure periods, fishes were anesthetized with phenoxyethanol $\left(3.0 \mathrm{~mL} \mathrm{~L}^{-1}\right)$ and had their liver and gills removed and immediately stored at $-80^{\circ} \mathrm{C}$ for subsequent biochemical analysis.

\subsection{Chemical analyses}

To confirm the nominal concentrations used in the tests, parabens concentrations were quantified using an Agilent Technologies series 1200 high-performance liquid chromatograph (HPLC) (Waldbronn, Germany), equipped with a diode array detector (DAD). The chromatography conditions were: Agilent Zorbax SB-C8 column $(250 \mathrm{~mm} \times$ $4.6 \mathrm{~mm} \times 5 \mu \mathrm{m}$ ) (Agilent Technologies, USA) and oven temperature of $25^{\circ} \mathrm{C}$. The mobile phase was a gradient of methanol (A) and wateracetic acid (1\%) (B). The gradient was as follows: $0 \mathrm{~min}-65 \% \mathrm{~A}: 35 \%$ B; $11 \mathrm{~min}-100 \% \mathrm{~A}: 0 \% \mathrm{~B} ; 16 \mathrm{~min}-65 \% \mathrm{~A}: 35 \% \mathrm{~B}$. The injection volume was $20 \mu \mathrm{L}$, flow rate of $1.0 \mathrm{~mL} \mathrm{~min}^{-1}$ and run time of $20 \mathrm{~min}$. Based on absorbance signals observed in the DAD spectrum of the standard solutions, parabens were detected and quantified at $258 \mathrm{~nm}$. The retention time found for methyl, ethyl, propyl, butyl and benzylparaben was $4.336,5.158,6.631,8.670$ and $9.107 \mathrm{~min}$, respectively. The linear correlation coefficient of the curve was $>0.99$ for all parabens. The precision in terms of repeatability, expressed as relative standard deviation (RSD), was $1.5 \%$ for methylparaben; $1.2 \%$ for ethylparaben; $1.6 \%$ for propylparaben and butylparaben; and $1.7 \%$ for benzylparaben. The detection limit for methyl, ethyl, propyl, butyl and benzylparaben was $0.03 ; 0.03 ; 0.05 ; 0.07$ and $0.08 \mathrm{mg} \mathrm{L}^{-1}$, respectively. The quantification limit was $0.13 \mathrm{mg} \mathrm{L}^{-1}$ for methyl, ethyl and propylparaben, $0.18 \mathrm{mg} \mathrm{L}^{-1}$ for butylparaben and $0.25 \mathrm{mg} \mathrm{L}^{-1}$ for benzylparaben.

\subsection{Biochemical analyses}

\subsubsection{Enzyme assays and protein quantification}

Liver and gills were weighed and homogenized (1:4, w/v) in buffer solution $\left(20.0 \mathrm{mmol} \mathrm{L}^{-1}\right.$ Tris, $1.0 \mathrm{mmol} \mathrm{L}^{-1}$ EDTA, $1.0 \mathrm{mmol} \mathrm{L}^{-1} \mathrm{DL}-$ Dithiothreitol, $0.5 \mathrm{~mol} \mathrm{~L}^{-1}$ sucrose and $0.15 \mathrm{~mol} \mathrm{~L}^{-1} \mathrm{KCl}, \mathrm{pH} 7.5$ ) containing $1.0 \mathrm{~mol} \mathrm{~L}^{-1}$ protease inhibitor (PMSF). The homogenized samples were centrifuged at $7426 \mathrm{~g}$ for $20 \mathrm{~min}$ at $4{ }^{\circ} \mathrm{C}$. The supernatant 
was collected and then centrifuged at $50,000 \mathrm{~g}$ for one hour at $4{ }^{\circ} \mathrm{C}$. The resulting supernatant fraction was used for SOD, CAT, GPx and GR assays.

SOD activity was measured by the inhibition of cytochrome $c$ reduction by the superoxide radicals that were generated by the xanthine/xanthine oxidase system at $550 \mathrm{~nm}$ (McCord and Fridovich, 1969). CAT activity was quantified at $240 \mathrm{~nm}$ by the $\mathrm{H}_{2} \mathrm{O}_{2}$ decomposition according to Beutler (1975). GPx activity was determined by the oxidation of NADPH (linked to GSSG reduction by excess glutathione reductase) at $340 \mathrm{~nm}$, as described by Sies et al. (1979). GR activity was quantified by the NADPH oxidation at $340 \mathrm{~nm}$, according to Carlberg and Mannervik (1985). Protein levels were measured by Bradford (1976) method using bovine serum albumin as standard.

\subsubsection{Total glutathione levels}

Total glutathione (GSH-t) content, comprising the sum of oxidized plus reduced glutathione, was measured by the Tietze (1969) method adapted by Akerboom and Sies (1981). Tissues (liver and gill) were weighed and homogenized in perchloric acid $0.5 \mathrm{M}(1: 9, \mathrm{w} / \mathrm{v})$, and centrifuged for $2 \mathrm{~min}$ at $15,000 \mathrm{~g}$ at $4{ }^{\circ} \mathrm{C}$. After centrifugation, the supernatant fraction was neutralized with $\mathrm{K}_{3} \mathrm{PO}_{4}$ and the GSH-t was determined by continuous reduction of 5,5V-dithiobis, 2-nitrobenzoic acid (DTNB) in the presence of oxidized glutathione (GSSG), glutathione reductase (GR) and $\mathrm{NADPH}$, at $412 \mathrm{~nm}$.

\subsubsection{Lipid peroxidation}

Lipid peroxidation was evaluated by the measurement of MDA levels. Tissues (gills and liver) were weighed and homogenized in Tris buffer $0.1 \mathrm{M}(1: 3, \mathrm{w} / \mathrm{v}), \mathrm{pH}$ 8.0. Then $0.3 \mathrm{~mL}$ of a thiobarbituric acid (TBA) solution ( $40 \mathrm{mg}$ in $10 \mathrm{~mL}$ of $\mathrm{HCl} 0.2 \mathrm{M}$ ) was added to homogenized sample and incubated for $40 \mathrm{~min}$ at $90^{\circ} \mathrm{C}$. Next, $1 \mathrm{~mL}$ of $\mathrm{n}$ butanol was added and samples were centrifuged at $1123 \mathrm{~g}$ for $3 \mathrm{~min}$ to extract the MDA-TBA derivatives. The supernatant was collected and the MDA-TBA derivatives were quantified by ultra-high performance liquid chromatography (UHPLC) at $532 \mathrm{~nm}$ (Almeida et al., 2003, 2004). The UHPLC system (Prominence Nexera XR, Shimadzu) consisted of DGU20A 3 degasser, LC-20 $\mathrm{CE}_{\mathrm{XR}}$ pump, and diode array detector (SPD-M20A) and fluorescence detector (RF-20A). The chromatographic conditions were: Shim-pack XR-ODS II column $(3.0 \times 100 \mathrm{~mm}, 2.2 \mu \mathrm{m})$, column temperature $40^{\circ} \mathrm{C}$, injection volume of $4 \mu \mathrm{L}$, isocratic mobile phase of a potassium phosphate solution $0.05 \mathrm{M}$ (pH 7.0) with $40 \%$ methanol and flow rate of $0.5 \mathrm{~mL} \mathrm{~min}^{-1}$. To quantify MDA-TBA derivatives, a MDA standard calibration curve was previously prepared using the same procedure used for the samples.

\subsection{Statistical analyses}

For acute toxicity tests, the $\mathrm{LC}_{50}-48 \mathrm{~h}$ values with their $95 \%$ confidence intervals for each paraben were calculated by the Probit method (USEPA, 2002). Biochemical biomarkers data were first checked for normality (Shapiro-Wilk's test) and homogeneity of variances (Bartlett's test), and then subjected to one-way analysis of variance (ANOVA). A post hoc multiple comparisons Dunnett's test was carried out when differences were revealed in data that followed a normal distribution. When the normality test failed, a non-parametric Kruskal-Wallis test was used. In statistical tests, differences were considered significant when $\mathrm{p} \leq 0.05$. All analyses were performed using Statistica 7.0 software (Statsoft, 2004).

\section{Results}

\subsection{Abiotic variables of the toxicity tests and chemical analysis}

During toxicity tests, the $\mathrm{pH}$ values of test solutions remained within the range of 7.1 and 7.8 and did not vary by more than 1.0 unit in any given test. The temperature in all toxicity tests varied between 25.4 and
Table 1

Values of $\mathrm{LC}_{50}-48 \mathrm{~h}$ for acute toxicity of five parabens and their respective $95 \%$ confidence intervals (CI) obtained for Nile tilapia (Oreochromis niloticus).

\begin{tabular}{ll}
\hline Parabens & $\mathbf{L C}_{\mathbf{5 0}}(\mathbf{9 5 \%} \mathbf{C I})\left(\mathbf{m g ~ \mathbf { L } ^ { - 1 }}\right)$ \\
\hline Benzylparaben & $7.98(5.38-11.83)$ \\
Butylparaben & $7.80(6.16-9.89)$ \\
Propylparaben & $17.36(14.63-20.61)$ \\
Ethylparaben & $24.08(18.70-31.02)$ \\
Methylparaben & $67.11(56.61-79.57)$ \\
\hline
\end{tabular}

$28.9^{\circ} \mathrm{C}$. Thus, all tests met the validity criteria set forth in the USEPA guidelines (USEPA, 2002).

Analysis of the test solutions in HPLC-DAD showed that the actual exposure concentrations in acute toxicity tests and biochemical assays with all parabens differed by less than $10 \%$ from the nominal concentrations. Measured chemical values are given in Supplementary material Tables S1 and S2.

\subsection{Acute toxicity}

At the end of the tests, the mortality in control and solvent control did not exceed $10 \%$ for all parabens tested, as recommended by the USEPA guidelines (2002). The $\mathrm{LC}_{50}-48 \mathrm{~h}$ mean values obtained for each compound in toxicity tests are shown in Table 1 . The toxicity of benzylparaben for Nile tilapia was similar to butylparaben, with no significant difference between them $(p>0.05)$. In this study, both benzylparaben and butylparaben were the most toxic and methylparaben was the least toxic to Nile tilapia.

Some changes in tilapia behavior were observed during the acute toxicity tests, such as rotation around the longitudinal axis, high excitation and loss of balance after a few minutes of exposure to parabens. With continued exposure, these animals remained immobile in the bottom of the aquarium. However, after $24 \mathrm{~h}$ of exposure, fish treated with low concentrations of parabens returned to normal behavior. Fish dead after exposure to high concentrations of parabens showed redness around the gills and darker coloring.

\subsection{Enzyme activity}

The SOD activity was significantly increased in Nile tilapia gills exposed to BeP and parabens mixture after 6 days of treatment. After 12 days, EtP, PrP, BuP, BeP and mixture also caused an increase in SOD activity in gills in relation to control group (Fig. 1A). In liver, the SOD activity was increased after 6 days of exposure to BuP and, in contrast, its activity was decreased in animals exposed to mixture. After 12 days, $\mathrm{MeP}$ and EtP induced an increase in the SOD activity in fish liver (Fig. 1B).

In Nile tilapia gills, the CAT activity was not altered by any treatment after 6 and 12 days of exposure (Fig. 1C). However, CAT activity was increased in liver of animals exposed to MeP and EtP after 6 days of treatment. After 12 days of exposure, CAT activity in Nile tilapia liver showed no significant difference when compared to control (Fig. 1D).

The GPx activity in gills was significantly higher in tilapias exposed for 6 days to MeP, EtP and PrP, compared to control values. After 12 days, EtP, BeP and mixture caused an increased in GPx activity in gills (Fig. 1E). In liver, after 6 days of exposure to parabens mixture, the GPX activity was increased and after 12 days of experiment, there was an increase of GPx activity in groups exposed to BuP and BeP (Fig. 1F).

In Nile tilapia gills, the GR activity was increased only in group exposed to PrP for 6 days. However, it was observed that GR activity in fish group exposed to mixture after 12 days of experiment was reduced (Fig. 1G). In liver, despite the GR activity did not show changes in relation to control group after 6 days of treatment, fish exposed to MeP, EtP and mixture for 12 days significantly increased the GR activity 
A

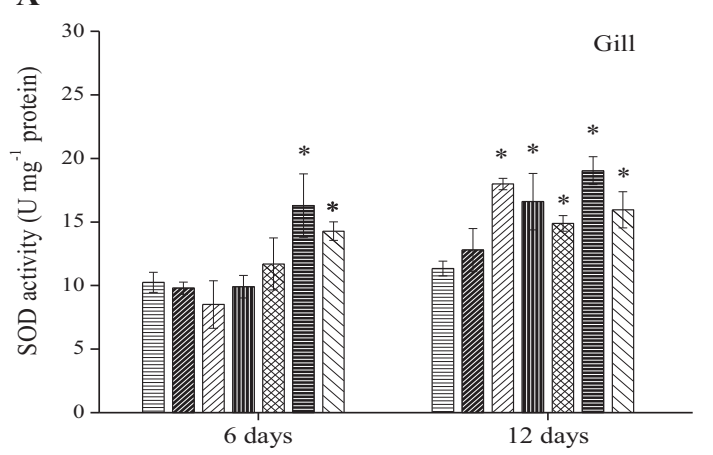

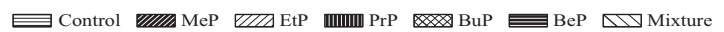

C

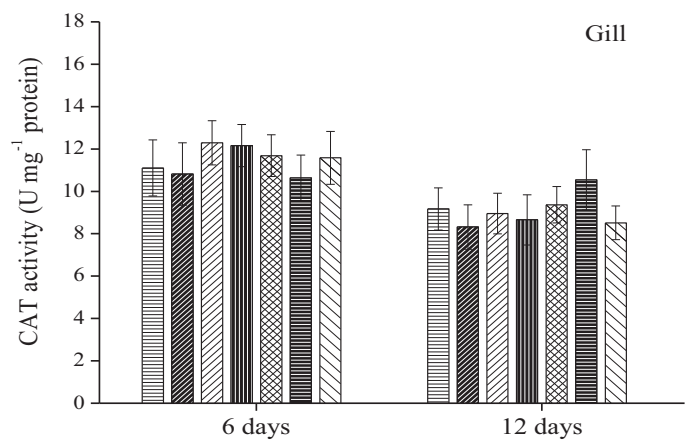

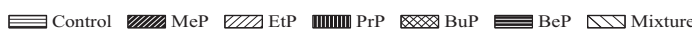

\section{$\mathbf{E}$}

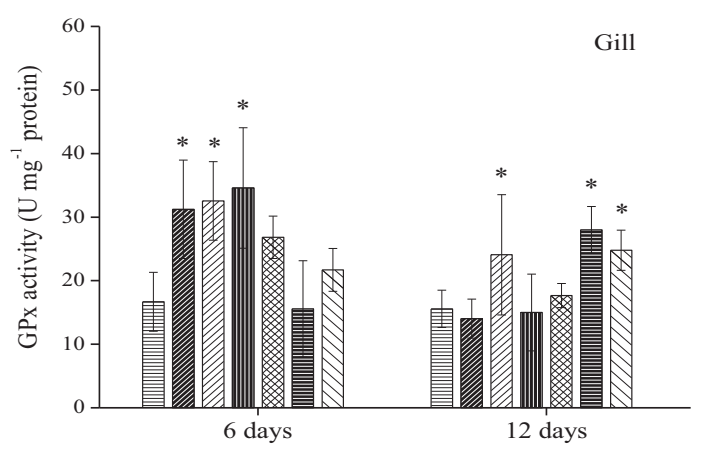

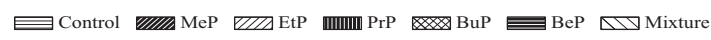

G

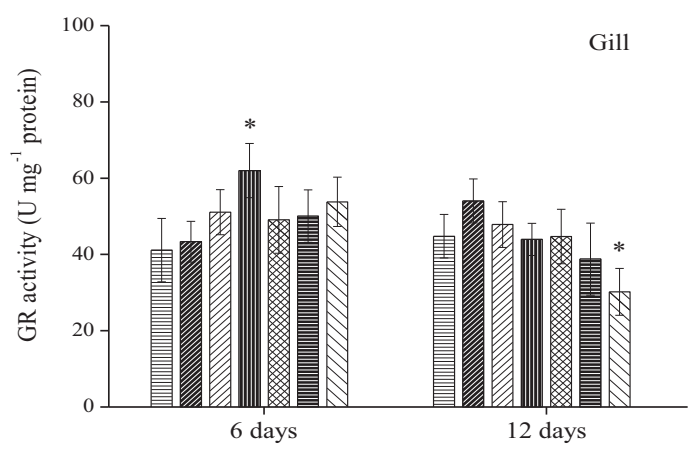

B

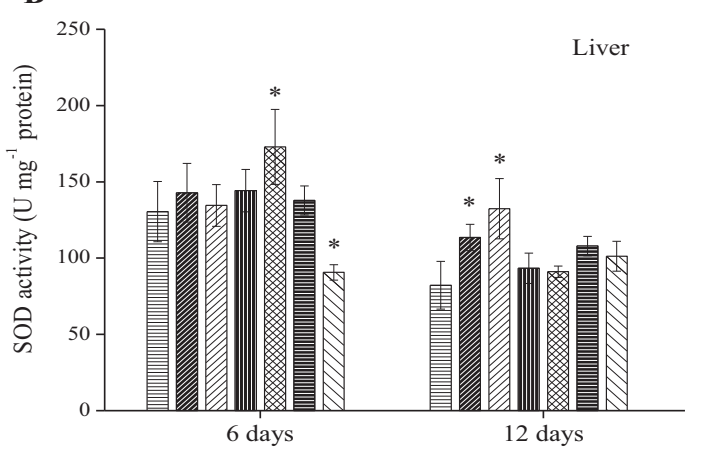

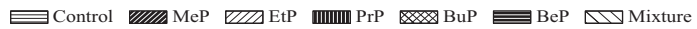

D

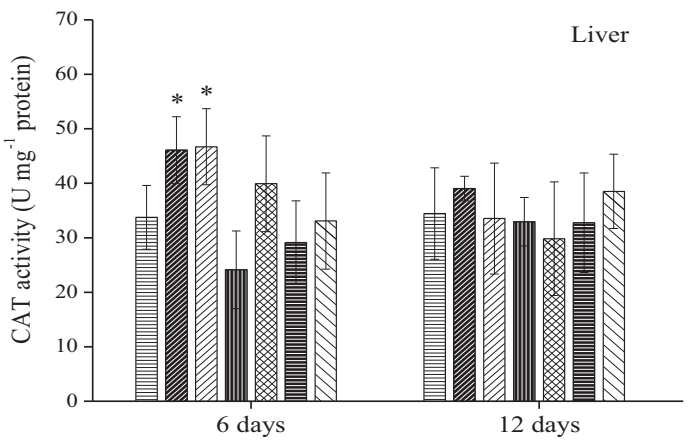

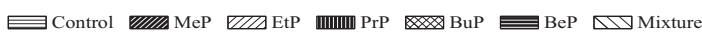

$\mathbf{F}$

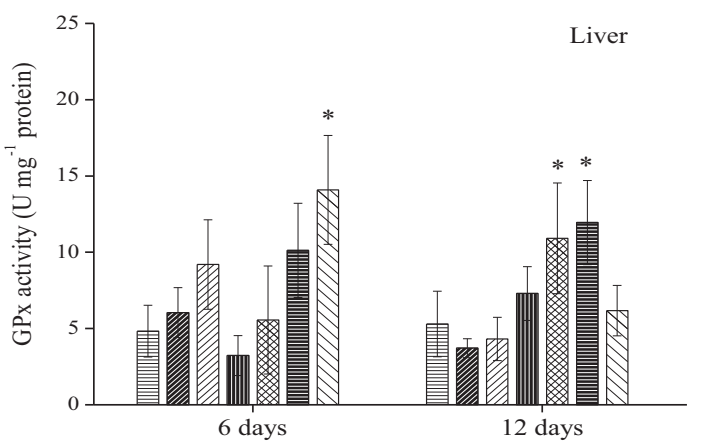

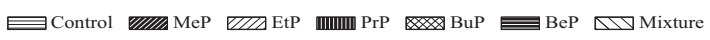

$\mathbf{H}$

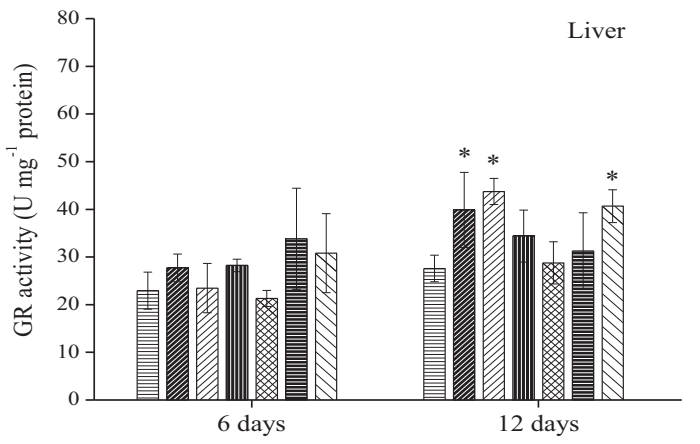

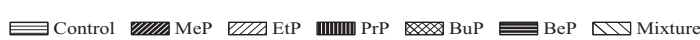

Fig. 1. Antioxidant enzyme activities in gill (A, C, E, G) and liver (B, D, F, H) of Oreochromis niloticus after 6 and 12 days of exposure to methylparaben (MeP), ethylparaben (EtP), propylparaben (PrP), butylparaben (BuP), benzylparaben (BeP) and mixture (MeP + PrP). Asterisk (*) indicates value significantly different from control $(\mathrm{p}<0.05)$. 
A

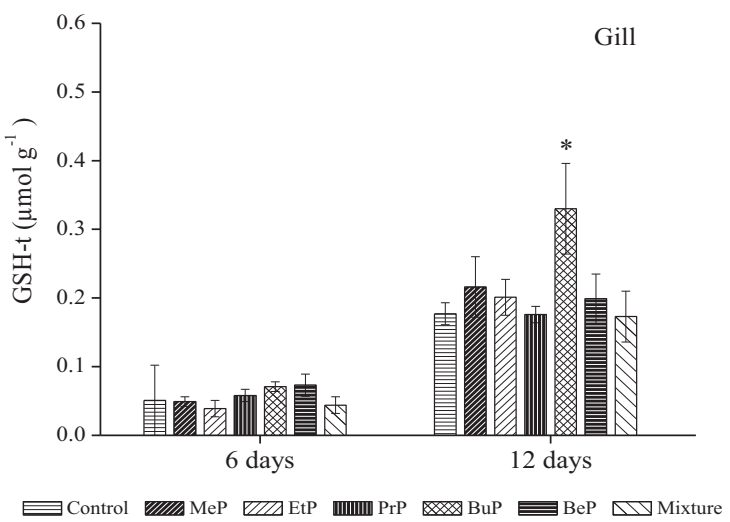

B

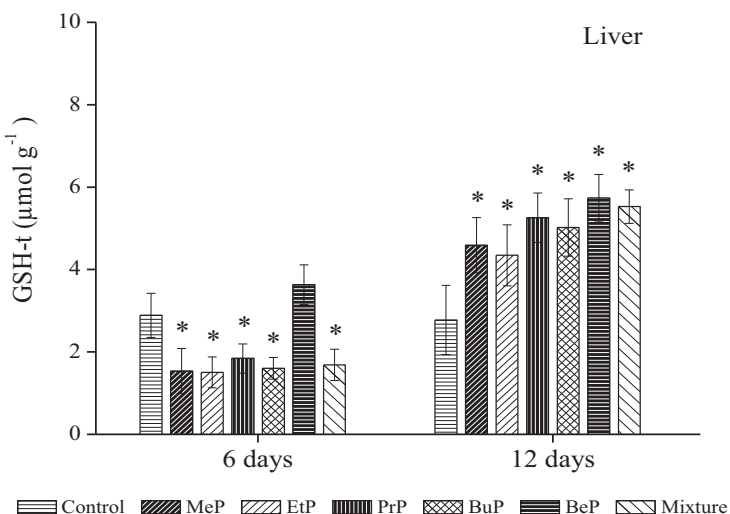

Fig. 2. Total glutathione (GSH-t) levels in gill (A) and liver (B) of Oreochromis niloticus after 6 and 12 days of exposure to methylparaben (MeP), ethylparaben (EtP), propylparaben $(\mathrm{PrP})$, butylparaben $(\mathrm{BuP})$, benzylparaben $(\mathrm{BeP})$ and mixture $(\mathrm{MeP}+\mathrm{PrP})$. Asterisk $(*)$ indicates value significantly different from control $(\mathrm{p}<0.05)$.

(Fig. 1H).

\subsection{GSH-t levels}

GSH-t levels remained unchanged in fish gills in all treatments after 6 and 12 days of exposure, except for animals exposed to BuP for 6 days that increased the GSH-t content (Fig. 2A). However, in tilapia liver, the GSH-t content significantly decreased after 6 days of exposure to MeP, EtP, PrP, BuP and mixture. In contrast, after 12 days, the GSH-t level increased in tilapia liver in all treatments when compared to control group (Fig. 2B).

\subsection{MDA levels}

The MDA levels in gills showed no significant differences after 6 and 12 days of exposure to parabens compared to control (Fig. 3A). In liver, there was only a decrease in concentration of MDA in the groups exposed to EtP, BuP and mixture after 12 days (Fig. 3B).

\section{Discussion}

The 48-h $\mathrm{EC}_{50}$ mean values calculated for parabens indicated that butyl and benzylparaben are more toxic to Nile tilapia than methyl, ethyl and propylparaben. Dobbins et al. (2009) also found that benzyl and butylparaben were more toxic to fish larvae of Pimephales promelas $\left(\mathrm{LC}_{50}=3.3 \mathrm{mg} \mathrm{L}^{-1}\right.$ and $4.2 \mathrm{mg} \mathrm{L}^{-1}$, respectively) than ethyl and

A

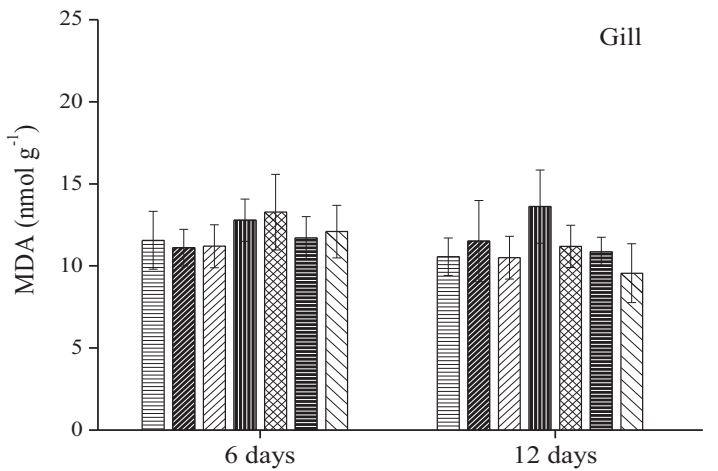

(Control ma MeP methylparaben $\left(\mathrm{LC}_{50}=34.3 \mathrm{mg} \mathrm{L}^{-1}\right.$ and $>160 \mathrm{mg} \mathrm{L}^{-1}$, respectively). Several studies have shown a relationship between the alkyl-chain length of paraben and its toxicity (Terasaki et al., 2009; Yamamoto et al., 2011), indicating that as chain length of parabens increase, the toxicity to aquatic organisms increase concomitantly. This can be explained by the fact that pollutants with high lipophilicity (higher octanol/ water partition coefficients) are more powerful to penetrate the cell membrane, leading to greater toxicity (Gao et al., 2016).

Dobbins et al. (2009) suggested that a possible toxic action mode of parabens in invertebrates and fish may be narcosis. Narcosis (or baseline toxicity) denotes the minimal effects caused by nonspecific disturbance of membrane integrity and functioning as a result of partitioning of chemical into cell membranes (Escher and Hermens, 2002). According to Van Wezel and Opperhuizen (1995), the accumulation of pollutants in lipophilic portion of aquatic organisms can cause narcosis, and consequently reversible loss of mobility, or death of the organisms (Sandermann, 2008). In the present study, loss of mobility and fish death was verified after exposure to parabens. Furthermore, changes in fish behavior and characteristics (redness around the gills and darker coloring) observed during paraben acute toxicity tests are considered common responses in laboratory studies with fish after exposure to pollutants that cause narcosis (Van Wezel and Opperhuizen, 1995). As expected under the Meyer-Overton rule, the narcotic activity of parabens in Nile tilapia may have increased with lipophilicity.

Considering the acute toxicity values, there is a limited risk for fish exposed to parabens in the environment. Yamamoto et al. (2011)

B

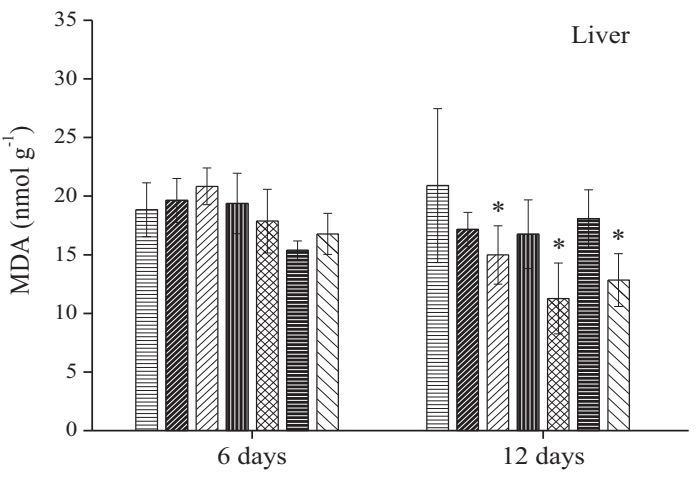

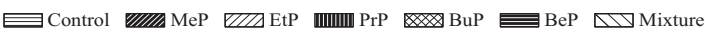

Fig. 3. Malondialdehyde (MDA) levels in gill (A) and liver (B) of Oreochromis niloticus after 6 and 12 days of exposure to methylparaben (MeP), ethylparaben (EtP), propylparaben (PrP), butylparaben (BuP), benzylparaben (BeP) and mixture (MeP + PrP). Asterisk $(*)$ indicates value significantly different from control $(\mathrm{p}<0.05)$. 
conducted preliminary ecological risk assessments for seven parabens using toxicological data from algae, cladocerans and fish and they also found low risk of all the parabens to aquatic organisms. However, it is important to emphasize that there is a potential for parabens to cause estrogenic responses and oxidative stress in aquatic organisms at concentrations lower than those that may cause acute toxicity (Brausch and Rand, 2011; Comeche et al., 2017; Yamamoto et al., 2011).

In this study, the results indicated that exposure to parabens cause biochemical changes inside cells, which in turn modulate the enzymes activity in Nile tilapia. The activity of SOD, GPx and GR in gills and liver of Nile tilapia exposed to most parabens presented a significant increase, showing that the antioxidant system was activated. This increased activity of antioxidant enzymes in fish exposed to parabens demonstrated that there was an increase in ROS in the liver and gills, but the Nile tilapia showed no signs of lipid peroxidation in the analyzed tissues, indicating that antioxidant defenses were efficient to neutralize ROS. SOD has important role in withdrawal of ROS by protecting the organisms from oxidative stress. SOD is the enzyme that catalyzes dismutation of the superoxide anion to $\mathrm{O}_{2}$ and $\mathrm{H}_{2} \mathrm{O}_{2}$, being the first defense mechanism against ROS. In fish gills, after $12 \mathrm{~d}$ of exposure, all parabens tested, except MeP, caused an increase in SOD. Gills were a major target for parabens probably due to their wide surface area in contact with the external medium and reduced distance between internal and external medium (Ameur et al., 2015). In liver, the tested paraben mixture $(\mathrm{MeP}+\mathrm{PrP})$ inhibited SOD, but its activity was restored to normal after $12 \mathrm{~d}$ of exposure. Furthermore, MeP and EtP enhanced SOD activity in liver.

CAT and GPx play complementary roles in the elimination of $\mathrm{H}_{2} \mathrm{O}_{2}$, and GPx is also involved in the reduction of organic hydroperoxides by GSH oxidation (Hermes-Lima, 2004). The increase in GPx activity in gills and liver reinforces the idea of an increase in concentration of $\mathrm{H}_{2} \mathrm{O}_{2}$ in these organs caused by exposure to parabens. Although there was an increase in liver CAT after $6 \mathrm{~d}$ of exposure to MeP and EtP, the activity of this enzyme in the liver and gills was not very representative for this fish. Thus, we can infer that in Nile tilapia the GPx in the gills and liver is acting with greater intensity in the elimination of reactive species than the CAT. In fish gills, increased GPx activity following PrP exposure enhanced GSH utilization, which assumed an oxidized form (GSSG) and subsequently elevated the activity of GR to maintain a sufficient amount of reduced equivalents in the cells, necessary for cell protection against oxidative stress. GR is responsible for catalyzing the reduction of GSSG to GSH at the expense of nicotinamide adenine dinucleotide phosphate (NADPH) (Sthijns et al., 2016). In animals treated with mixture, although GPx activity increased after $12 \mathrm{~d}$, the GR activity was reduced in the gills. This GR reduction may have been caused by the inhibition of glutathione synthesis enzymes (i.e., g-glutamyl cysteine synthetase and GSH synthetase) or decrease in the availability of NADPH.

GSH-t levels were also modulated after treatments with parabens. Glutathione (GSH) acts as a primordial electron donor in the reduction of $\mathrm{H}_{2} \mathrm{O}_{2}$ and organic peroxides (Almeida et al., 2011). In Nile tilapia, liver was more responsive to modulation of GSH content than gills. As liver is the prime organ involved in metabolism of the compounds, it is prone to be attacked by the free radicals produced by them (Shah and Verma, 2011). In this study, the GSH-t content in liver decreased after 6 $\mathrm{d}$ of exposure to parabens probably due to the presence of free radicals generated by oxidative stress. However, after $12 \mathrm{~d}$, the GSH-t levels increased in tilapia liver in all treatments, indicating an antioxidant adaptation to exposure to sublethal concentrations of parabens. In contrast, Shah and Verma (2011) reported that GSH levels were significantly reduced in treated mice with paraben due to excessively produced free radicals which surpassed the scavenging potency of this antioxidant.

Regarding the MDA levels, alterations were not observed in gills compared to control group and in fish liver, MDA content was reduced after $12 \mathrm{~d}$ of exposure to EtP, BuP and mixture (MeP + PrP), indicating no lipid peroxidation in the analyzed tissues. In this study, resistance development in Nile tilapia is related with increased antioxidant defenses, which were important in the protection against oxidative stress caused by parabens, inhibiting lipid peroxidation. Enzymatic and nonenzymatic antioxidants were related to decrease in MDA levels in fish exposed to EtP (SOD, GR, GSH-t), BuP (GPx, GSH-t) and mixture (GR, GSH-t). Shah and Verma (2011) verified that the administration of BuP for 30 days induced lipid peroxidation through reduction in the enzymatic activities of SOD, CAT, GPx and GR in mice liver leading to hepatotoxicity. Overall, our results for fish were different from those reported for invertebrates and rodents in several studies (e.g. Comeche et al., 2017; Nishizawa et al., 2006; Popa et al., 2011), evidencing that the effects of parabens are species-specific. Our results also showed that adaptive responses of fish antioxidant system were dependent on exposure time, since prolonged exposures (6 and 12 days) to sublethal concentrations favored the resistance development of Nile tilapia to parabens. As reported by Sthijns et al. (2016), the dose, the compound tested and the timing of exposure influence the adaptive mechanisms to oxidative stress, specifically the GSH system. Therefore, in studies evaluating oxidative damage, not only dose or compound, but also time, should be considered.

\section{Conclusion}

The present study demonstrates that parabens exposure induced alterations in the antioxidant enzyme activities and the non-enzymatic antioxidant content in gills and liver of Nile tilapia in order to neutralize the oxidative effect of generated ROS. The increase in SOD, GPx and GR activities and GSH-t level ensured the protection of Nile tilapia against oxidative stress caused by parabens, since no sign of lipid peroxidation was observed in tissues analyzed. In addition, prolonged exposure to sublethal concentrations favored the resistance development of Nile tilapia to parabens. Considering the increased use of parabens by the human population and the continuous release of these compounds in aquatic environments, adaptive responses of the antioxidant system are crucial for the health of this fish. Our results show that the antioxidant defenses of Nile tilapia were efficient and the biochemical changes induced by parabens were important in the protection against oxidative damages.

\section{Acknowledgement}

We thank the "Fundação de Amparo à Pesquisa do Estado de São Paulo - FAPESP" for financial support (2012/00150-0 and 2012/ 01192-8).

\section{Appendix A. Supporting information}

Supplementary data associated with this article can be found in the online version at http://dx.doi.org/10.1016/j.ecoenv.2018.06.076.

\section{References}

Akerboom, T.P., Sies, H., 1981. Assay of glutathione, glutathione disulfide, and glutathione mixed disulfides in biological samples. Methods Enzymol. 77, 373-382.

Almeida, E.A., Marques, S.A., Klitzke, C.F., Bainy, A.C., De Medeiros, M.H., Di Mascio, P., Loureiro, A.P., 2003. DNA damage in digestive gland and mantle tissue of the mussel Perna perna. Comp. Biochem. Physiol. 135, 295-303.

Almeida, E.A., Miyamoto, S., Bainy, A.C., De Medeiros, M.H., Di Mascio, P., 2004. Protective effect of phospholipid hydroperoxide glutathione peroxidase (PHGPx) against lipid peroxidation in mussels Perna perna exposed to different metals. Mar. Pollut. Bull. 49 (5-6), 386-392.

Almeida, E.A., Silva, H., Grunig, D., Bainy, A.C.D., Freitas, F.P., Motta, F.D., Gomes, O.F., Medeiros, M.H.G., Di Mascio, P., 2011. Evaluation of glutathione status in aquatic organisms. Oxidative Stress in Aquatic Ecosystems, pp. 381-388.

Alslev, B., Korsgaard, B., Bjerregaard, P., 2005. Estrogenicity of butylparaben in rainbow trout Oncorhynchus mykiss exposed via food and water. Aquat. Toxicol. 72 (4), 295-304.

Ameur, W.B., El Megdiche, Y., Lapuente, J., Barhoumi, B., Trabelsi, S., Ennaceur, S., 
Camps, L., Serret, J., Ramos-López, D., Gonzalez-Linares, J., Touil, S., Driss, M.R., Borràs, M., 2015. Oxidative stress, genotoxicity and histopathology biomarker responses in Mugil cephalus and Dicentrarchus labrax gill exposed to persistent pollutants. A field study in the Bizerte Lagoon: Tunisia. Chemosphere 135, 67-74.

Ateş, P.S., Ünal, İ., Üstündağ, Ü.V., Alturfan, A.A., Yiğitbaşı, T., Emekli-Alturfan, E., 2018. Methylparaben induces malformations and alterations on apoptosis, oxidant-antioxidant status, ccnd1 and myca expressions in zebrafish embryos. J. Biochem. Mol. Toxicol. 32 (3), 1-6.

Beutler, E., 1975. Red Cell Metabolism: A Manual of Biochemical Methods. Grune \& Stratton, New York.

Błędzka, D., Gromadzińska, J., Wąsowicz, W., 2014. Parabens. From environmental studies to human health. Environ. Int. 67, 27-42.

Bradford, M.M., 1976. Rapid and sensitive method for quantitation of microgram quantities of protein utilizing principles of protein-dye binding. Anal. Biochem. 72, 248-254.

Brausch, J.M., Rand, G.M., 2011. A review of personal care products in the aquatic environment: environmental concentrations and toxicity. Chemosphere 82 (11), 1518-1532.

Brown, S.E., Sant, K.E., Fleischman, S.M., Venezia, O., Roy, M.A., Zhao, L., Timme-Laragy, A.R., 2018. Pancreatic beta cells are a sensitive target of embryonic exposure to butylparaben in zebrafish (Danio rerio). Birth Defects Res. 1-16.

Carlberg, I., Mannervik, B., 1985. Glutathione reductase. Methods Enzymol. 113, 484-490.

Comeche, A., Martín-Villamil, M., Picó, Y., Varó, I., 2017. Effect of methylparaben in Artemia franciscana. Comp. Biochem. Physiol. Part C: Toxicol. Pharmacol. 199, 98-105.

Czarczyńska-Goślińska, B., Zgoła-Grześkowiak, A., Jeszka-Skowron, M., Frankowski, R., Grześkowiak, T., 2017. Detection of bisphenol A, cumylphenol and parabens in surface waters of Greater Poland Voivodeship. J. Environ. Manag. 204, 50-60.

Dambal, V.Y., Selvan, K.P., Lite, C., Barathi, S., Santosh, W., 2017. Developmental toxicity and induction of vitellogenin in embryo-larval stages of zebrafish (Danio rerio) exposed to methyl Paraben. Ecotoxicol. Environ. Saf. 141, 113-118.

Darbre, P.D., Harvey, P.W., 2008. Paraben esters: review of recent studies of endocrine toxicity, absorption, esterase and human exposure and discussion of potential human health risks. J. Appl. Toxicol. 28 (5), 561-578.

Dobbins, L.L., Usenko, S., Brain, R.A., Brooks, B.W., 2009. Probabilistic ecological hazard assessment of parabens using Daphnia magna and Pimephales promelas. Environ. Toxicol. Chem. 28 (12), 2744-2753.

Escher, B.I., Hermens, J.L., 2002. Modes of action in ecotoxicology: their role in body burdens, species sensitivity, QSARs and mixture effects. Environ. Sci. Technol. 36 (20), 4201-4217.

Galinaro, C.A., Pereira, F.M., Vieira, E.M., 2015. Determination of parabens in surface water from Mogi Guaçu River (São Paulo, Brazil) using dispersive liquid-liquid microextraction based on low density solvent and LC-DAD. J. Braz. Chem. Soc. 26, $2205-2213$.

Gao, Y., Ji, Y., Li, G., An, T., 2016. Theoretical investigation on the kinetics and mechanisms of hydroxyl radical-induced transformation of parabens and its consequences for toxicity: influence of alkyl-chain length. Water Res. 91, 77-85.

Hermes-Lima, M., 2004. Oxygen in biology and biochemistry: role of free radicals. In: Storey, K.B. (Ed.), Functional Metabolism: Regulation and Adaptation. Wiley-Liss, Publishing Inc., New Jersey, pp. 319-366.

Kang, S., Kim, S., Park, J., Kim, H.J., Lee, J., Choi, G., Choi, S., Kim, S.Y., Moon, H.B., Kho, Y.L., Choi, K., 2013. Urinary paraben concentrations among pregnant women and their matching newborn infants of Korea, and the association with oxidative stress biomarkers. Sci. Total Environ. 461, 214-221.

Ley, B.D., Mendaza, F.H., Gómez, L.C.S., 2006. Parabenos: ¿ mito o realidad? Piel 21 (5), 231-240.

Li, W., Gao, L., Shi, Y., Wang, Y., Liu, J., Cai, Y., 2016. Spatial distribution, temporal variation and risks of parabens and their chlorinated derivatives in urban surface water in Beijing, China. Sci. Total Environ. 539, 262-270.
McCord, J.M., Fridovich, I., 1969. Superoxide dismutase. An enzymic function for erythrocuprein (hemocuprein). Biol. Chem. 244, 6049-6055.

Nishizawa, C., Takeshita, K., Ueda, J., Nakanishi, I., Suzuki, K.T., Ozawa, T., 2006. Reaction of parahydroxybenzoic acid esters with singlet oxygen in the presence of glutathione produces glutathione conjugates of hydroquinone, potent inducers of oxidative stress. Free Radic. Res. 40 (3), 233-240.

Núñez, L., Turiel, E., Martin-Esteban, A., Tadeo, J.L., 2010. Molecularly imprinted polymer for the extraction of parabens from environmental solid samples prior to their determination by high performance liquid chromatography-ultraviolet detection. Talanta 80 (5), 1782-1788.

Popa, D.S., Kiss, B., Vlase, L., Pop, A., Iepure, R., Păltinean, R., Loghin, F., 2011. Study of oxidative stress induction after exposure to bisphenol a and methylparaben in rats. Farmacia 59 (4), 539-549.

Ramaswamy, B.R., Kim, J.W., Isobe, T., Chang, K.H., Amano, A., Miller, T.W., Siringanf, F.P., Tanabe, S., 2011. Determination of preservative and antimicrobial compounds in fish from Manila Bay, Philippines using ultra high performance liquid chromatography tandem mass spectrometry, and assessment of human dietary exposure. J. Hazard. Mater. 192 (3), 1739-1745.

Sakuragui, M.M., Paulino, M.G., Pereira, C.D.S., Carvalho, C.S., Sadauskas-Henrique, H., Fernandes, M.N., 2013. Integrated use of antioxidant enzymes and oxidative damage in two fish species to assess pollution in man-made hydroelectric reservoirs. Environ. Pollut. 178, 41-51.

Sandermann, H., 2008. Ecotoxicology of narcosis: stereoselectivity and potential target sites. Chemosphere 72 (9), 1256-1259.

Shah, K.H., Verma, R.J., 2011. Butyl p-hydroxybenzoic acid induces oxidative stress in mice liver ñ an in vivo study. Acta Pol. Pharm. Drug Res. 68 (6), 875-879.

Sies, H., Koch, O.R., Matino, E., Boveris, A., 1979. Increased biliary glutathione disulfide release in chronically ethanol-treated rats. FEBS Lett. 103 (2), 287-290.

Soni, M.G., Carabin, I.G., Burdock, G.A., 2005. Safety assessment of esters of p-hydroxybenzoic acid (parabens). Food Chem. Toxicol. 43, 985-1015.

Statsoft, 2004. Inc., STATISTICA (data analysis software system), version 7.0.

Sthijns, M.M., Weseler, A.R., Bast, A., Haenen, G.R., 2016. Time in redox adaptation processes: from evolution to hormesis. Int. J. Mol. Sci. 17 (10), 1649-1664.

Tavares, R.S., Martins, F.C., Oliveira, P.J., Ramalho-Santos, J., Peixoto, F.P., 2009. Parabens in male infertility- Is there a mitochondrial connection? Reprod. Toxicol. 27, $1-7$.

Terasaki, M., Kamata, R., Shiraishi, F., Makino, M., 2009. Evaluation of estrogenic activity of parabens and their chlorinated derivatives by using the yeast two-hybrid assay and the enzyme-linked immunosorbent assay. Environ. Toxicol. Chem. 28, 204-208.

Terasaki, M., Takemura, Y., Makino, M., 2012. Paraben-chlorinated derivatives in river waters. Environ. Chem. Lett. 10, 401-406.

Tietze, F., 1969. Enzymic method for quantitative determination of nanogram amounts of total and oxidized glutathione: applications to mammalian blood and other tissues. Anal. Biochem. 27 (3), 502-522.

USEPA - US Environmental Protection Agency, 2002. Methods for measuring the acute toxicity of effluents and receiving waters to freshwater and marine organisms. Washington, DC.

Van Wezel, A.P., Opperhuizen, A., 1995. Narcosis due to environmental pollutants in aquatic organisms: residue-based toxicity, mechanisms, and membrane burdens. Crit. Rev. Toxicol. 25 (3), 255-279.

Xue, J., Kannan, K., 2016. Accumulation profiles of parabens and their metabolites in fish, black bear and birds, including bald eagles and albatrosses. Environ. Int. 94, 546-553.

Xue, J., Sasaki, N., Elangovan, M., Diamond, G., Kannan, K., 2015. Elevated accumulation of parabens and their metabolites in marine mammals from the United States coastal waters. Environ. Sci. Technol. 49 (20), 12071-12079.

Yamamoto, H., Tamura, I., Hirata, Y., Kato, J., Kagota, K., Katsuki, S., Yamamoto, A. Kagami, Y., Tatarazako, N., 2011. Aquatic toxicity and ecological risk assessment of seven parabens: individual and additive approach. Sci. Total Environ. 410, 102-111. 